TB cases occurred with tofacitinib treatment. One malignancy (thyroid cancer) was reported. Severe ( $>3$ ULN) elevation of liver enzymes or increases of CPK above normal were infrequent $(<1 \%)$; no severe cytopenias were reported. Lipid increases occurred in $10 \%$ of pts. Tofacitinib was withdrawn in 40 pts $(13.9 \%)$ due to lack of efficacy $(n=20 ; 7 \%)$, AEs $(n=11 ; 3.8 \%)$ or other reasons $(n=9 ; 3.1 \%)$, such as loss of follow-up, pregnancy, access issues or travel. Limitations include limited pt numbers and follow-up of exposure.

Conclusions: In the RW LA setting, tofacitinib was used mostly as 2nd-line therapy; no new safety signals emerged vs clinical trials. SIEs and HZ were uncommon; no cases of TB/other Ols occurred, but were seen in the clinical program.

Acknowledgements: This study was sponsored by Pfizer Inc. Editorial support was provided by $\mathrm{K}$ Irving of $\mathrm{CMC}$ and funded by Pfizer Inc.

Disclosure of Interest: E. Schneeberger: None declared, A. Salas Speakers bureau: AbbVie, Pfizer Inc, L. F. Medina: None declared, J. B. Zacariaz: None declared, R. D. Mantilla Grant/research support from: Abbott, AbbVie, Biopas, Bristol-Myers Squibb, Novartis, Pfizer Inc, Roche, Consultant for: Abbott, AbbVie, Biopas, Bristol-Myers Squibb, Novartis, Pfizer Inc, Roche, Speakers bureau: Abbott, AbbVie, Biopas, Bristol-Myers Squibb, Novartis, Pfizer Inc, Roche, J. C. Sarmiento-Monroy: None declared, L. J. Elizondo Grant/research support from: Amgen, Roche, Consultant for: Instituto Mexicano del Seguro Social, B. Garro: None declared, H. Madariaga: None declared, L. Górriz: None declared, R. D. N. Giorgi: None declared, M. Pinheiro Shareholder of: Pfizer Inc, Employee of: Pfizer Inc, D. Ponce de Leon Shareholder of: Pfizer Inc, Employee of: Pfizer Inc DOI: 10.1136/annrheumdis-2017-eular.1607

\section{AB0420 THE SAME TREATMENT RESPONSE OF MONO- AND COMBINED-MTX TREATMENT IN DMARDS-NAIIVE TURKISH PATIENTS WITH SEROPOSITIVE RHEUMATOID ARTHRITIS AND THE IMPORTANCE OF PULMONARY TOXICITY}

F.F. Ayhan ${ }^{1,2}$, A. Gümüştepe ${ }^{1}$, B. Nacır ${ }^{1}$, A. Karagöz ${ }^{1} .{ }^{1}$ Physical medicine \& rehabilitation, Ankara Training and Research Hospital, Ankara; ${ }^{2}$ Physical therapy \& rehabilitation, Uşak University, School of Health Sciences, Uşak, Turkey

Background: Methotrexate (MTX) is the anchor drug for the treatment of rheumatoid arthritis (RA). There are important guidelines suggesting mono-MTX treatment at first for pharmacologic treatment of RA $(1,2)$. We thought that these recommendations should be evaluated in different geographic regions and ethnic groups because of genetic factors.

Objectives: Therefore, we aimed to compare the efficacy and adverse effect profile of mono-MTX and combined-MTX treatments in patients with DMARDsnaïve Turkish patients with seropositive RA.

Methods: Hundred patients with seropositive RA (mean age: $47.4 \pm 12.0$ years, 63 females and 37 males) were included. Patients were excluded the past history of using for synthetic or biologic DMARDs or moderate-high dose steroid (>10mg/day), viral hepatitis, transaminase elevations, and other contra-indications for MTX. Then they were divided as mono-MTX $(n=57)$ and combined-MTX $(n=43)$ groups.

Results: There was no difference between groups in age $(p=0.34)$, sex $(p=0.104)$, age of onset $(p=0.10)$, MTX-weekly dose $(p=0.228)$, the score of DAS28 $(p=0.783), R F$ level $(p=0.473)$, and CCP level $(p=0.592)$ at the beginning. Patients of combined-DMARDs group used higher dose of prednisolone than patients of mono-MTX group $(p=0.011)$. The change of DAS28 scores was not different between groups. CRP levels of combined-MTX group were higher than mono-MTX group both beginning and at 6th month. The frequencies of adverse events were not different between groups. Gl adverse events are the first line in both groups (28\% vs. $16.3 \%$ ). The frequencies of dose decrease $(7 \%$ vs. $14 \%)$ or stop $(7 \%$ vs. $4.7 \%)$ for MTX were also not different between groups ( $p=0.288, p=0.257$ ). The frequencies of other adverse effects were less than $5 \%$. MTX dose decrease or stop have been moderately correlated with pulmonary involvement $(r=0.4$, $\mathrm{p}=0.02$ ).

Conclusions: Both mono-MTX and combined-MTX treatment had similar efficacy and safety profile in Turkish patients with seropositive RA as reported in studies of other countries suggesting no any advantage of combined MTX compared to mono-MTX (3). The frequency of MTX-stopping in our study was similar to this systematic review $(9 \%)$. As a conclusion, MTX should also be the first choice of the treatment of RA in our country. Pulmonary adverse events should not be ignored.

References:

[1] Singh JA, Saag KG, Bridges SL J, et al. 2015 American College of Rheumatology Guideline for the Treatment of Rheumatoid Arthritis. Arthritis Rheumatol. 2016;68(1):1-26.

[2] Smolen JS, Landewé R, Breedveld FC, et al. EULAR recommendations for the management of rheumatoid arthritis with synthetic and biological diseasemodifying antirheumatic drugs: 2013 update. Ann Rheum Dis. 2014;73(3):492509

[3] Katchamart W, Trudeau J, Phumethum V, et al. Methotrexate monotherapy versus methotrexate combination therapy with non-biologic disease modifying anti-theumatic drugs for RA. Cochrane Database od Systematic Reviews 2010; Issue 4.Art.No.:CD008495.

Disclosure of Interest: None declared

DOI: 10.1136/annrheumdis-2017-eular.2147

\section{AB0421 RAPAMYCIN REDUCES DISEASE ACTIVITY THROUGH RESTORING REGULATORY T CELL NUMBERS IN PATIENTS WITH ACTIVE REFRACTORY RHEUMATOID ARTHRITIS}

H. Niu ${ }^{1}$, Z. Li ${ }^{1}$, J. He ${ }^{1}$, R. Jia ${ }^{1}$, J. Luo ${ }^{1}$, C. Gao ${ }^{2}$, C. Wang ${ }^{1}$, X. Li ${ }^{1}$ ${ }^{1}$ Department of Rheumatology, the Second Hospital of Shanxi Medical University, Taiyuan, China; ${ }^{2}$ Department of Pathology, Brigham and Women's Hospital, Harvard Medical School, Boston, United States

Background: $\mathrm{CD} 4^{+} \mathrm{CD} 25^{+} \mathrm{Foxp}^{+} \mathrm{T}$ regulatory (Treg) cells play a key role in peripheral tolerance. Rapamycin was approved by the FDA to preserve renal allografts and to be efficacious in patients with several autoimmune diseases [1]. Objectives: To investigate the status of Treg cells in active refractory rheumatoid arthritis (RA) and the effects of rapamycin on patients with RA.

Methods: Forty-five active refractory RA patients were enrolled. Rapamycin was used at a dose of $0.5 \mathrm{mg}$ every 2 days [the preliminary, open-label clinical trial of rapamycin (Clinical Trials.gov number: ChiCTR-IPR-17010307)]. Clinical improvement and immunological assessments were performed before 1st rapamycin dose and 12 weeks post treatment. Blood samples were obtained from RA patients and 75 healthy volunteers for estimation of $\mathrm{CD}^{+} \mathrm{T}$ cell subsets.

Results: Two patients dropped out due to non-compliance. As compared to healthy controls (median of Treg cells: $33.32 \mathrm{cell} / \mathrm{ul}$ ), the absolute counts of circulating Treg cells were significantly decreased in patients with active refractory RA (median: $27.17 \mathrm{cell} / \mathrm{ul} ; P=0.046$ ). While the median ratios of Th17/Treg cells in patients with active refractory RA (median: 0.26 ) were significantly higher than those of healthy volunteers (median: $0.19 ; P=0.029$ ). No difference in the absolute counts of circulating Th17 cells and Th1 cells was observed between patients with active refractory RA and healthy subjects. Rapamycin treatment led to clinical improvement with the median post-treatment DAS28-ESR decreasing when compared to baseline (from 4.19 to 3.78 ) in active refractory RA patients. Sixteen patients (16/43 patients, 37.21\%) achieved an EULAR moderate response and 6 patients (6/43 patients, $13.95 \%)$ reached good response at week 12 . Rapamycin administration resulted in an increase in the absolute counts of Treg cells in active refractory RA patients, from a median of $27.17 \mathrm{cell} / \mathrm{ul}$ (at week 0 ) to 37.57 cell/ul (at week 12) $(P=0.041)$. The ratios of Th17/Treg cells shows a reduction from a median of 0.26 at baseline to 0.20 at week 12 , but the difference is not significant $(P=0.376)$. No significant difference was observed in the absolute counts of circulating Th17 and Th1 cells after rapamycin treatment. Interestingly, we observed that Treg cells increased before the complete remission of the disease (DAS28 score $<2.6$ ) in patients with active refractory RA. At week 12, the mean dose of prednisone which refractory RA patients were receiving decreased from $11.98 \mathrm{mg} / \mathrm{d}$ to $8.31 \mathrm{mg} / \mathrm{d}$, with a dose reduced by $>30 \%$ than that at baseline. The categories of DMARDs use were also reduced $(P<0.05)$. No serious adverse events was observed during the 12-week period of rapamycin treatment.

Conclusions: Reduced absolute number of Treg cells was found in the patients with active refractory RA, indicating an imbalance between Th17 and Treg cells. Rapamycin elicits rapid improvement of disease activity via restoring circulating Treg cells numbers in patients with active refractory RA.

References:

[1] Perl A. Activation of mTOR (mechanistic target of rapamycin) in rheumatic diseases. Nat Rev Rheumatol. 2016. 12(3): 169-82.

Disclosure of Interest: None declared

DOI: 10.1136/annrheumdis-2017-eular.270

\section{AB0422 1,25-DIHYDROXYVITAMIN D3 MODULATES T CELLS DIFFERENTIATION AND IMPACTS ON THE PRODUCTION OF ASSOCIATED-CYTOKINES FROM CHINESE HAN PATIENTS WITH EARLY RHEUMATOID ARTHRITIS}

H. Wen ${ }^{1}, \mathrm{X} . \mathrm{Li}^{2} .{ }^{1}$ Rheumatology; ${ }^{2}$ the Second Hospital of Shanxi Medical University, Taiyuan, China

Background: Recent studies have suggested that vitamin D may play a role in select inflammatory diseases including rheumatoid arthritis (RA). Epidemiological studies suggest that there is an association between vitamin $D$ deficiency and susceptibility to RA.

The present study sought to investigate effects of 1,25-dihydroxyvitamin D3 $(1,25(\mathrm{OH}) 2 \mathrm{D} 3)$ on $\mathrm{T}$ cells differentiation and associated cytokines in Chinese Han patients with early rheumatoid arthritis (RA). The results reported that $1,25(\mathrm{OH}) 2 \mathrm{D} 3$ inhibits the synthesis of Th1 cytokines IFN- $\gamma$, Th17 cytokines IL-17, IL-22, IL-6, TNF- $\alpha$, and up-regulates Th2 cytokine IL-4, which indicated that the possible immunoregulatory role and bone-sparing effects of $1,25(\mathrm{OH}) 2 \mathrm{D} 3$ in RA through modulation of the Th1/Th17 and Th2 cytokine balance.

Objectives: To study effects of 1,25-dihydroxyvitamin $\mathrm{D} 3\left(1,25(\mathrm{OH})_{2} \mathrm{D}_{3}\right)$ on $\mathrm{T}$ cells differentiation and associated cytokines in patients with early rheumatoid arthritis (RA).

Methods: The level of Th1, Th2, Th17 and Treg cell were detected with BDFACS Calibur flow cytometer. IFN- $\gamma$, TNF- $\alpha$, IL-2, IL-4, IL-6, IL-10, IL-17 and IL-22 were examined in 54 patients with incipient RA using a cytometric bead array (CBA).

Results: After 72 hours of incubation of peripheral blood mononuclear cells (PBMCs) with $1,25(\mathrm{OH})_{2} \mathrm{D}_{3}$ in RA patients, the levels of IFN- $\gamma$, TNF- $\alpha$, IL-2, IL-6 and IL-17 significantly decreased compared to those of the control. $1,25(\mathrm{OH})_{2} \mathrm{D}_{3}$ had no significantly impact on the levels of IL-4, IL-10 and IL-22. The levels of Th17 and the ratio of Th17/Treg significantly decreased in $1,25(\mathrm{OH})_{2} \mathrm{D}_{3}$ treated 
groups compared to those of the control. $1,25(\mathrm{OH})_{2} \mathrm{D}_{3}$ had no significantly impact on the level of Th1, Th2, Treg and the ratio of Th1/Th2.

Conclusions: The present study demonstrated that $1,25(\mathrm{OH})_{2} \mathrm{D}_{3}$ inhibits the synthesis of Th1 cytokines IFN- $\gamma$, Th17 cytokines IL-17, IL-22, IL-6, TNF- $\alpha$, and upregulates Th2 cytokine IL-4, which indicated that the possible immunoregulatory role and bone-sparing effects of $1,25(\mathrm{OH})_{2} \mathrm{D}_{3}$ in RA through modulation of the Th1/Th17 and Th2 cytokine balance.

\section{References:}

[1] Smolen JS, Aletaha D, McInnes IB. Rheumatoid arthritis. Lancet 2016 May 3. pii: S0140-6736(16)30173-8. doi: 10.1016/S0140-6736(16)30173-8. [Epub ahead of print].

[2] Wen H, Baker JF. Vitamin D, immunoregulation, and rheumatoid arthritis. J Clin Rheumatol 2011;17(2):102-7.

[3] $\mathrm{H}$. Takayanagi. Osteoimmunology and the efects of the immune system on bone. Nature Reviews Rheumatology 2009;5:667-76.

[4] N. J. Horwood, V. Kartsogiannis, J. M. W. Quinn, et al. Activated T lymphocytes support osteoclast formation in vitro. Biochemical and Biophysical Research Communications 1999:265(1):144-50.

[5] Y. Choi, K. M. Woo, S. H. Ko et al. Osteoclastogenesis is enhanced by activated $\mathrm{B}$ cells but suppressed by activated CD8+ T cells. European Journal of Immunology 2001:31(7):2179-88.

Acknowledgements: This work was supported by a Research Grant from the National Natural Science Foundation of China (no.81301532) and the Shanxi Science and Technology research projects of China (no.201603D321074).

The authors thank Dr Alexis Ogdie for reviewing the manuscript.

Disclosure of Interest: None declared

DOI: 10.1136/annrheumdis-2017-eular.3177

\section{AB0423 MINIMALLY INVASIVE SURGICAL TREATMENT OF TEMPOROMANDIBULAR JOINT IN PATIENTS WITH VARIOUS RHEUMATIC DISORDERS}

I. Zaslavskiy ${ }^{1}$, A. Drobyshev ${ }^{1}$, T. Dubinina ${ }^{2}$, S. Erdes ${ }^{2}$, A. Kuznetsov ${ }^{1} .{ }^{1}$ A.I. Yevdokimov Moscow State University of Medicine and Dentistry; " "Va Nasonova Research Institute of Rheumatology, RUSSIA, MOSCOW, Moscow, Russian Federation

Background: Currently, maxillofacial surgery to actively develop and improve minimally invasive surgical methods for the treatment of patients with diseases of temporomandibular joint (TMJ). These types of surgical treatments like arthroscopy and artrolavazh TMJ are less traumatic and therefore can be effective in patients with rheumatic pathology.

Objectives: To evaluate the efficacy of minimally invasive surgical treatment of $T M J$ in patients with rheumatic diseases (RD).

Methods: In the study were included 64 pts aged from 18 to 65 years with various rheumatic disorders and lesions of the TMJ. Of these, rheumatoid arthritis (RA) $43(67.2 \%)$, psoriatic arthritis (PsA) $11(17.2 \%)$, systemic lupus erythematosus $8(12.5 \%)$ and ankylosing spondylitis (AS) - $2(3.1 \%)$. Before and after 14 days, a month and 6 months after surgery were assessed the following parameters: the level of pain in the TMJ (VAS), the aperture of mouth opening. All the patients at baseline and at 6 months after treatment was performed MRI of the TMJ. Interpretation of the TMJ MRI studies performed by the presence of signs of pathological changes in the joint, which were scored according to the number of pathological signs (from 0 to 8 points). As a preparatory stage before surgery all patients - splint therapy during 1 month was performed. Surgery included arthrolavage and arthroscopy TMJ followed by the introduction of hyaluronic acid. Results: Before treatment all patients had severe involvement of the TMJ by Wilkes international classification: III of St is $62.5 \%$, IV - by $21.9 \%, \mathrm{~V}-15,6 \% .6$ months after surgical treatment the level of pain in the TMJ decreased 9.8 times (from 4.9 to $0.5, p<0,0001$ ). Mouth opening increased 2.3 times (from $17.5 \mathrm{~mm}$ to $40.9 \mathrm{~mm}, p<0,0001$ ), was reached from $96.7 \%$ of patients normal value. In the control MRI study of the TMJ at 6 months after surgery, the quantity of signs of pathological changes in the joints were reduced by 2.7 times in comparison with the initial level. The best results were achieved in patients with RA and PsA. The lowest result was achieved in the group of patients with AS.

Conclusions: Minimally invasive methods of surgical treatment of TMJ (arthrolavage and arthroscopy), the most effective and appropriate for the treatment of patients with RD lesion of the temporomandibular joint.

Disclosure of Interest: None declared

DOI: 10.1136/annrheumdis-2017-eular.4562

\section{AB0424 THE EFFECT OF HIGH LEVEL OF ANTI-CITRULLINATED PROTEIN ANTIBODIES AND RHEUMATOID FACTOR ON BONE EROSIONS IN PATIENTS WITH EARLY RHEUMATOID ARTHRITIS- A CROSS-SECTIONAL AND LONGITUDINAL ANALYSIS}

J. Yue $^{1}$, J. Griffith ${ }^{2}$, J. Xu ${ }^{3}$, L. Shi ${ }^{1}$, D. Wang ${ }^{4}$, P. Wong ${ }^{1}$, E.K. Li ${ }^{1}$, M. Li ${ }^{1}$, T.K. Li ${ }^{1}$, T.Y. Zhu ${ }^{5}$, L. Qin ${ }^{5}$, L.-S. Tam ${ }^{1} .{ }^{1}$ Department of Medicine \& Therapeutics, The Prince of Wales Hospital, The Chinese University of Hong Kong; ${ }^{2}$ Department of Imaging and Interventional Radiology, The Prince of Wales Hospital, The Chinese University of Hong Kong: ${ }^{3}$ Department of
Orthopedics \& Traumatology: ${ }^{4}$ Department of Imaging and Interventional Radiology; ${ }^{5}$ Bone Quality and Health Center of the Department of Orthopedics \& Traumatology, The Prince of Wales Hospital, The Chinese University of Hong Kong, Hongkong, Hong Kong

Background: Bone erosions are a key feature of rheumatoid arthritis (RA) reflecting both disease severity and disease progression. Recent studies using HR-pQCT demonstrated impairment in the bone microstructure of the metacarpophalangeal (MCP) joints of ACPAs-positive healthy individuals despite no signs of arthritis. In patients with established RA, ACPAs and rheumatoid factor (RF) showed an additive effect on erosion number and erosion size. Furthermore, RF influences erosion size only in ACPAs-positive but not in ACPAs-negative patients. Objectives: To determine the effect of high titre of anticitrullinated protein antibodies (ACPAs) and rheumatoid factor (RF) on the number and size of bone erosions in patients with early rheumatoid arthritis (ERA) by high-resolution peripheral quantitative computed tomography (HR-pQCT) at baseline and whether these antibodies are associated with the progression of erosion after one year of follow-up.

Methods: In the cross-sectional study, HR-pQCT of the second metacarpophalangeal joint (MCP2) was performed in 124 patients with ERA at baseline, images were analysable in 117 patients. Erosions were visualized in 72 patients and parameters of bone erosions were assessed. In the prospective study, 63 ERA patients who had completed one year of follow-up with repeat HR-pQCT scan were also analysed. The number and volume of the erosions as well as bone mineral density (BMD) surrounding erosion were quantified. Data on demographic and disease-specific parameters including ESR, CRP, DAS 28, ACPAs and RF levels and treatment were recorded.

Results: At baseline, 90/117 patients were both ACPAs and RF positive (ACPAs+/RF+ group), $7 / 117$ were only RF (RF+), $13 / 117$ were only ACPAs (ACPAs+) and $7 / 117$ were antibody negative (non-ACPAs+/RF+ group, $n=27$ ). Erosion depth and volume were increased in the ACPAs+/RF+ group compared with the non-ACPAs+/RF+ group (both $\mathrm{P}<0.05$ ) (Table 1 ). Independent explanatory variables associated with a larger erosion volume included $R F>16 \mathrm{U}(\mathrm{P}=0.012)$, older age $(P=0.003)$ and a higher damage joint count $(P=0.028)$. Images from 63 patients who completed 12 months follow-up were analysed. Erosion volume were significantly lower in patients who achieved simplified disease activity score (SDAl) remission at 12 months compared to those who did not $(P=0.045)$. Linear regression analysis indicated that independent predictors for an increase in erosion volume included $R F>16 \mathrm{U}(\mathrm{P}=0.032)$ and a higher damage joint count $(P=0.009)$ at baseline and failure to achieve SDAl remission at 1 year $(P=0.043)$.

\begin{tabular}{|c|c|c|c|c|}
\hline parameters & Total sample & RFt/ACPAst & Not $\mathrm{RF}+/ \mathrm{ACPA}+$ & Pvalue \\
\hline $\mathrm{N}$ (total) & 117 & 90 & 27 & \\
\hline Females $\mathrm{N}(\%)$ & $87(74.36 \%)$ & $66(73.33 \%)$ & $21(77.78 \%)$ & 0.500 \\
\hline Age (years) & $53.024 \pm 13.0155$ & $52.993 \pm 13.0250$ & $53.129 \pm 13.2313$ & 0.962 \\
\hline $\begin{array}{l}\text { Discase duration } \\
\text { (months) }\end{array}$ & $7.1207 \pm 5.15862$ & $7.4157 \pm 5.31466$ & $6.1481 \pm 4.56326$ & 0.265 \\
\hline $\operatorname{ESR}\left(\mathrm{mm} / \mathrm{1}^{t} \mathrm{hr}\right)$ & $58.955 \div 32.6734$ & $59.942+34.5028$ & 55.704 26.0455 & 0.497 \\
\hline CRP(m/dal) & $18.738 \div 10.950$ & $18.712 \pm 26.4026$ & $18.822+19.0308$ & 0.984 \\
\hline DAS28-CPR(4) & $4.8615 \pm 0.92659$ & $4.8068 \pm 0.92384$ & $5.0418 \pm 0.92999$ & 0.250 \\
\hline DAS28-ESR(4) & $6.8612 \pm 1.05333$ & $6.8406 \pm 1.05429$ & $6.9291 \pm 1.06729$ & 0.704 \\
\hline SDAI score & $28.0363 \pm 11.14522$ & $27.7124 \div 10.94763$ & $29.1041 \pm 11.92582$ & 0.572 \\
\hline HАQ & $1.02283+0.742946$ & $0.96449+0.664134$ & $1.21296+0.946155$ & 0.129 \\
\hline $\begin{array}{l}\text { Tender joint count (0- } \\
\text { 68) }\end{array}$ & $8.00(5-12.75)$ & $8.00(5-12)$ & $8.00(4-15)$ & 0.345 \\
\hline $\begin{array}{l}\text { Swollen joint count (0- } \\
\text { 66) }\end{array}$ & $5.00(2-7)$ & $4.00(2.5-7)$ & $5.00(2-6)$ & 0.780 \\
\hline $\begin{array}{l}\text { Damage joint count (0. } \\
\text { 68) }\end{array}$ & $2.00(1-3)$ & $2.00(1-3)$ & $2.00(1-4)$ & 0.485 \\
\hline \multicolumn{5}{|l|}{ Treatment } \\
\hline no & 82 & 62 & 20 & 0.50 \\
\hline ever & 16 & 12 & 4 & 0.52 \\
\hline current & 19 & 14 & $s$ & 0.49 \\
\hline Erosions(MCP2,N) & 135 & 109 & 26 & \\
\hline Erosions/patients(N) & 1.1538 & 1.2111 & 0.96296 & 0.307 \\
\hline Width(mm) & $2.7218 \pm 1.87087$ & $2.7729 \pm 2.02280$ & $2.5558 \pm 1.34248$ & 0.531 \\
\hline Depth(mm) & $1.0686 \pm 0.88600$ & $1.1392+0.98107$ & $0.8615 \div 0.44234$ & 0.048 \\
\hline Volume(mm3) & $4.4756 \pm 6.38831$ & $5.3472+5.98738$ & $1.8312+1.38206$ & 0.017 \\
\hline BMD $(\mathrm{mg} / \mathrm{cm} 3)$ & $423.8868+103.8231$ & $420.1646+109.6622$ & $431.2889+83.10927$ & 0.585 \\
\hline
\end{tabular}

Conclusions: ACPAs and RF show an additive effect on erosion volume in ERA patients. Higher RF titre was associated with larger erosion volume at baseline and predicted progression of erosion volume after adjusting for baseline parameters and treatment response.

Disclosure of Interest: None declared

DOI: 10.1136/annrheumdis-2017-eular.2962 